\title{
Integrated Process Planning and Scheduling in Networked Manufacturing Systems for Industry 4.0: A Review and Framework Proposal
}

\author{
Maria L. R. Varela ${ }^{1}$, Goran D. Putnik ${ }^{2}$, Vijay K. Manupati ${ }^{3}$, Gadhamsetty Rajyalakshmi ${ }^{4}$, \\ Justyna Trojanowska ${ }^{5}$, José Machado ${ }^{6}$ \\ \{leonilde@dps.uminho.pt ${ }^{1}$, putnikgd@dps.uminho.pt ${ }^{2}$, manupativijay@gmail.com ${ }^{3}$, \\ rajyalakshmi@vit.ac.in ${ }^{4}$, justyna.trojanowska@put.poznan.pl ${ }^{5}$, jmachado@ dem.uminho.pt ${ }^{6}$ \} \\ ${ }^{1,2}$ Department of Production and Systems, School of Engineering, University of Minho, Portugal \\ ${ }^{3,4}$ School of Mechanical Sciences, VIT University, Vellore, Tamil Nadu, India \\ ${ }^{5}$ Poznan University of Technology, Chair of Management and Production Engineering, Poland \\ ${ }^{6}$ Department of Mechanical Engineering, School of Engineering, University of Minho, Portugal
}

\begin{abstract}
Integrated process planning and scheduling in networked manufacturing systems plays a crucial role nowadays and in the forthcoming context of Industry 4.0 to enable effective and efficient decisions, and to improve the business market, based on collaboration, along with computer-based distributed manufacturing and management functions. In this paper some insights regarding a literature review carried out about this main subjects analysed are presented and discussed. Moreover, a framework for integrated process planning and scheduling in networked manufacturing systems is proposed and briefly described, along with some main underlying issues, which are further discussed.
\end{abstract}

Keywords: Integrated process planning and scheduling, networked manufacturing, Industry 4.0.

\section{Introduction}

In order to respond to today's intensely competitive environment and to obtain high product variety and customization, along with short product life cycles, networked manufacturing environments, along with integrated production planning and scheduling systems play a crucial role to shift manufacturing and management paradigms from deterministic to a more rigorous, autonomous and dynamically adaptive control based on a flexible, agile and collaborative manufacturing. A befitting answer to this need is based on integrated production planning and scheduling through networked manufacturing (NM). Liu [1] define networked manufacturing as a set of manufacturing activities ranging from market control, manufacturing technologies and manufacturing systems that can help enterprises to improve the business management and enhance their competitiveness in the market. Therefore, the study and analysis of networked manufacturing has become a necessity due to its advantages in current competitive atmosphere, as it meets a number of, often conflicting, objectives and goals, such as reducing the manufacturing cycle time, shorter lead times, better interoperability, and maintaining the production flexibility leading to many feasible process plans, and all these requirements can be fulfilled through IPPS based on appropriate 
supporting technologies for enabling integration, interoperability and digitalization, for reaching imperative main and common enterprise goals.

Although the monolithic approach of traditional manufacturing has its own advantage, it is not sufficient in the current highly dynamic changing manufacturing environment occurring in the scope of Industry 4.0 or I4.0 for short. However, several problems related to the traditional manufacturing approach have been clearly stated [2]. To overcome these problems, researchers have realized that there is a need to integrate both the functions and the means to achieve better performance of the system. Subsequently, the need to integrate both of these issued activities have found the basis in the context of networked and collaborative manufacturing environments.

However, no conventional shop floor control system based on centralized or hierarchical control architecture can handle the required adaptive and autonomous control of manufacturing system. Therefore, the control architecture is gradually being shifted to the distributed, decentralized and autonomous control (DDAC) architecture. Since DDAC shop floor control system may have complete local autonomy, governing the reconfigurability, scalability as well as fault tolerance, which it is suitable for a dynamically changing environment in the scope of I4.0.

To achieve the successful information and knowledge exchange between different facilities, there is a need for internet and communication technology IoT (internet of things) through which it can be possible to link all of them. Some of the key literature reviews for planning and scheduling and their integration, regarding learning and other AI-based approaches, for instance based on multi-agent systems (MAS), or on other kind of approaches, such as simulation based, among others, are further detailed in this paper.

The main objective of this paper is to analyse, synthesise and present a comprehensive systematic literature review (SLR) of the role of integrated process planning and scheduling in networked manufacturing environments.

In an initial analysis of the selected literature of 51 research papers a framework was designed, which was used to elaborate on findings of this review, which will be referred to and discussed further in this paper. The structure of the paper is as follows. Section 2 briefly describes networked manufacturing systems. Section 3 discusses integrated production planning and scheduling, in general, and through underlying requisites regarding knowledge acquisition, and learning paradigms, along with knowledge management, data visualization and interpretation issues. Section 4 refers to enterprise modelling and integration, in a broad sense, and presents a proposed framework for an IIPS in the context of I4.0. Finally, section 5 provides some main conclusions and planned future work.

\section{Networked Manufacturing Systems}

In networked manufacturing, job requests come from different customers with competitive relationships, i.e. the job scheduling concentrates on satisfying the individual objectives of each job. However, in a networked manufacturing environment, the machines with different capabilities are distributed geographically to perform various operations of the products.

As a new and advanced manufacturing paradigm, networked manufacturing pattern suits the global trends towards a knowledge-based economy and global manufacturing environment. In networked manufacturing environments, the mode of production has shifted from make-to-stock to make-to-order, in which the active participation of customers, 
submitting job requests, which tend to be highly customized, to the manufacturing system are accomplished [3].

A networked manufacturing system (NMS) can be defined as a manufacturing-oriented network that employs the Internet and other related technologies to cater the needs of distributed manufacturing environments. It has the capability to encapsulate the manufacturing enterprises' information and to provide the manufacturing services through which interoperability between enterprises can be achieved.

The networked manufacturing environment is distinct from the traditional manufacturing environment in many ways, and summarized information about NMS is presented in Table 1. As can be realised through the information presented in Table 1, there is a set of fundamental functionalities required to enable to reach appropriate NMS.

Table 1. Functionalities of Networked Manufacturing Systems (NMS)

\begin{tabular}{cl}
\hline Functionalities & \multicolumn{1}{c}{ Description } \\
\hline System Monitoring & $\begin{array}{l}\text { It is the monitoring done by the intelligent systems to make it more } \\
\text { dynamic and efficient }\end{array}$ \\
Information Consultation & $\begin{array}{l}\text { It is the input data gathered from the management teams, experts and } \\
\text { cloud. }\end{array}$ \\
Manufacturing Service & $\begin{array}{l}\text { It is the available service in the cloud to be provided if the current } \\
\text { service is finished or delay is caused. } \\
\text { Production Planning and Scheduling }\end{array}$ \\
& $\begin{array}{l}\text { It is the arranging, controlling and optimizing work and workloads in a } \\
\text { production process or manufacturing process }\end{array}$ \\
\hline
\end{tabular}

As mentioned by Li [4], in the case of the traditional manufacturing systems, process planning and scheduling functions aim to acquire optimal results for all the jobs, which are different from individual optimal results for each job. In networked based manufacturing, owing to the role played by the competition factors among different jobs, the objectives for process planning and scheduling is slightly different from that in traditional manufacturing.

In traditional manufacturing, the machines associated with jobs are located and constrained in a single workshop or enterprise. However, for networked based manufacturing jobs and machines are distributed in different workshops or enterprises located globally at larger distances. Thus it can be inferred that for networked based manufacturing situation, it is similar to one found in flexible manufacturing system where many possible machines, operations are feasible but not on the same shop floor.

Alternatively, it can be said that in networked manufacturing scenario, generation of optimal process plans for each job, in the presence of several dynamic constraints, such as the present status of machines, tools, and fixtures at a given manufacturing place, is posing a genuine challenge in the design and development of appropriate integrated production planning and scheduling systems.

\section{Integrated Production Planning and Scheduling}

In this section, an extensive literature is briefly presented and described, in order to further realise about the present status of research and methodology adopted in the IPPS on networked manufacturing environments. In recent years, the area of IPPS is playing a major role, particularly to the current emerging manufacturing paradigms in many ways in I4.0.

Process planning and scheduling problems are considered as a non-polynomial (NP) hard problem [5-7], thus there is no algorithm that provides the exact solution in polynomial time. 
In general, the solution of IPPS in manufacturing systems is carried out with mainly three kinds of approaches such as nonlinear process planning (NLPP), closed loop process planning (CLPP), and distributed process planning (DPP). The detailed description of these approaches and their features, advantages, and disadvantages [8-10] are summarized in Table 2.

Table 2. Different kind of approaches and their characteristics in IPPS

\begin{tabular}{|c|c|c|c|c|}
\hline S.no & $\begin{array}{c}\text { IPPS } \\
\text { approaches }\end{array}$ & Features & Advantages & Disadvantages \\
\hline 1 & NLPP & $\begin{array}{l}\text { 1. Alternative process plans exist which } \\
\text { offers ahigh degree of routing } \\
\text { flexibility to schedule. } \\
\text { 2. It can improve the off-line } \\
\text { scheduling performance so as to } \\
\text { quickly react to the disturbances on the } \\
\text { shop floor. } \\
\text { 3. Information flow is one-way i.e., } \\
\text { from process planning to production } \\
\text { planning. Thus, may be impossible to } \\
\text { achieve optimal results while } \\
\text { integrating the manufacturing } \\
\text { functions. } \\
\text { 4. Out of many alternative process } \\
\text { plans, some of them are not feasible } \\
\text { according to real-time shop status. } \\
\text { 5. It is highly complex to allocate the } \\
\text { resources to all the generated } \\
\text { alternative process plans. }\end{array}$ & $\begin{array}{l}\text { Providing all the } \\
\text { alternative process } \\
\text { plans enhances the } \\
\text { flexibility of the } \\
\text { process plans } \\
\text { therefore to achieve } \\
\text { optimal or near } \\
\text { optimal results. }\end{array}$ & $\begin{array}{l}\text { Due to providing all the } \\
\text { alternative process plans of } \\
\text { the parts, the problem is a } \\
\text { case of combinatorial } \\
\text { explosive. }\end{array}$ \\
\hline 2 & CLPP & $\begin{array}{l}\text { 1. Here, each generated process plan is } \\
\text { feasible based on the current shop floor } \\
\text { conditions. } \\
\text { 2. It is necessary to get the real time } \\
\text { information of the manufacturing } \\
\text { system for processing. } \\
\text { 3. The process planning and scheduling } \\
\text { departments have to be changed and } \\
\text { reorganized to get the full advantage. } \\
\text { 4. Due to the capability of capturing } \\
\text { real time information, it requires } \\
\text { upgraded hardware and software. } \\
5 \text {. The solution space is limited for } \\
\text { conducting subsequent operations of } \\
\text { the system. }\end{array}$ & $\begin{array}{l}\text { Based on the } \\
\text { current shop floor } \\
\text { status, all generated } \\
\text { process plans are } \\
\text { valuable. }\end{array}$ & $\begin{array}{l}\text { CLPP requires real -time } \\
\text { information and the current } \\
\text { process plans data. It is } \\
\text { very difficult to regenerate, } \\
\text { update the process plans } \\
\text { for each schedule. }\end{array}$ \\
\hline 3 & DPP & $\begin{array}{l}\text { 1. This method can integrate process } \\
\text { planning and scheduling functions } \\
\text { without generating superfluous process } \\
\text { plans. } \\
\text { 2. Parallel processing of process } \\
\text { planning and scheduling is possible. } \\
\text { 3. Due to the capability of capturing } \\
\text { real time information, it requires } \\
\text { upgraded hardware and software. } \\
\text { 4. With this approach, finding out a } \\
\text { feasible solution from large space in a } \\
\text { reasonable time is difficult. } \\
\text { 5. The process planning and scheduling } \\
\text { departments of an organization must be } \\
\text { reorganizing according to the } \\
\text { requirements. }\end{array}$ & $\begin{array}{l}\text { Collaboration, } \\
\text { integration, and } \\
\text { coordination is } \\
\text { possible with DPP } \\
\text { approach. }\end{array}$ & $\begin{array}{l}\text { The Integration approach is } \\
\text { hierarchical in nature thus } \\
\text { it is not possible to } \\
\text { optimize both process } \\
\text { plans and scheduling plans } \\
\text { simultaneously. }\end{array}$ \\
\hline
\end{tabular}


The basic idea behind an integrated approach for process planning and scheduling functions was first introduced by Chryssolouris [11, 12]. Sundaram [13] proposed a group scheduling algorithm in job shop environment to minimize the makespan and to balance the load for machines. Later, with the integration approach, the performance of the manufacturing system has been improved. Subsequently, several issues involved in the integration of manufacturing functions are addressed [14]. In their work, a dynamic feedback mechanism was introduced for effective coordination among various resources. They reported a significant impact on the system performance with a reduction in the number of late parts, total tardiness and flow times. Wang and Shen [15] proposed an integrated model and developed the concept of a dynamic feedback system for finding the alternative process plans for networked manufacturing system. Through their approach, the flexibility of the manufacturing system has been improved. Cai [16] stated that with NLPP approach an integration of the process planning and scheduling couldnot obtain the optimal results due to its one-way information flow. If the parts are huge in number, their alternative process plans are exponentially increasing in number which can create huge problem for data storage. Also, some of the process plans, out of all, are not feasible according to the real-time status of the manufacturing environment [17].

Shafaei and Brunn [18] introduced Flex Plan model for IPPS approach for the selection of suitable process plans by considering available manufacturing resources. Here, the authors successfully implemented the reactive re-planning approach to catering the disturbances occurring on the shop floor. A simulation based genetic algorithm approach for IPPS has been proposed by Lee and Kim [19]. Instead of creating the alternative process plans, in their work authors used agenetic algorithm for near-optimal process plan selection. To execute the performance measures, i.e. makespan and lateness, dispatching rules, such as shortest processing time (SPT), and earliest due date (EDD) rules were implemented. From the results, they have concluded that more than $20 \%$ of the reduction in makespan has been achieved through their approach, while comparing with random process planning selection operation.

Kumar and Rajotia [20] suggested an on-line scheduling approach in computer aided process planning for a job shop scheduling problem to determine the flow time and a number of tardy jobs. Subsequently, in the similar problem, the authors have considered machine capacity and cost while assigning the operations to the machines. The IPPS approach along with their developed decision support system, the parts processing has also been handled [21].

Zhou [22] proposed a GA-based IPPS approach to improve the scheduling objectives, such as minimize the makespan, minimizing the number of rejects, and to minimize the processing cost, in a job shop scheduling environment. The mentioned work has been extended by considering balancing the load on each machine. To solve this problem, a particle swarm optimization (PSO) algorithm has been proposed for effective results [23]. Li [24] developed a two-layer representation of GA based chromosomes for alternative process plan and scheduling plan string. With this effective genetic representation and operation scheme, IPPS approach has been adopted for job shop scheduling problem to minimize the makespan. They did also prove that integration approach performs far better than the traditional approach. Later, they modified the GA and proposed a hybrid GA by incorporating Tabu search to solve the job shop scheduling problem with IPPS. Instead of the previously mentioned two layer concept, they proposed a three-layer representation for process plan, scheduling, and machine string to minimize the makespan [25].

Moon [26] presented a topological short test technique and conducted different experiments by varying order size, number of operations, and resources selection rules to improve the performance of a supply chain by optimizing the makespan. It is important to find 
the maintenance cost of the obtained feasible process plan from many alternative process plans. Thus, Wang [5] proposed an IPPS approach for batch size production with simulated annealing algorithm to find optimal process plan in prismatic parts. In their approach, the authors correlated the tardiness and the cost of maintaining the process plan. From their results, it is clear that tardiness of a job has been improved by reducing the cost of process plan at a lower level.

Haddadzade [27] proposed an IPPS approach to handle the operations of complex prismatic components in a job shop environment and to minimize the due dates and the cost. Baykasoglu and Ozbakir [28] implemented an IPPS approach with generic process plan method to generate feasible process plans, and dispatching rule based heuristic to generate feasible schedules. To optimize the performance measures, such as flow time and cost of process plan, a multi-objective-based tabu search algorithm was employed. Results confirmed that an increase of process plan flexibility decreases the cost of process plan. Rajkumar [29] developed a multi-objective greedy randomized adaptive search procedure (GRASP) to minimize the makespan and to maximize the total workload, total flow time, and tardiness in the context of flexible job shop environment. The proposed approach was used to test four benchmark data sets, and it had demonstrated capability to solve IPPS problems. An IPPS approach in the context of Holonic manufacturing system to balance the load for all the machines is highlighted. Thereafter, to be part of solving the problem, a hybrid PSO algorithm and differential evolutionary algorithm has been proposed to find out the better results [30]. Nakandala [31] presented an integrated approach for manufacturing and distribution network within a supply chain context of a global car Company. The authors found that through the integrated approach, interfacing of individual networks has been eliminated. Furthermore, they also stated that for further improvements on the supply chain network the integrated approach is capable of providing flexibility, visibility, and maintainability.

Capturing dynamic behavior of the manufacturing system to perform the manufacturing functions is one of the complex tasks in a recent manufacturing environment. To deal with this problem, several researchers [11, 32-34] have proposed different models and methodologies. Chan [35] proposed a dynamic feature based IPPS approach for improving the smallest slack time criterion in a batch size production system. Moreover, an artificial intelligence based feature extractor model was implemented to extract the features of the product. Subsequently, a rough process plan was constructed by considering one machine setup on the shop floor to enhance the scheduling of batch size production. An N-person non-cooperative game-theoretic approach to generate the optimal process plans for multiple jobs in a networked-based manufacturing system was presented [30]. The networked manufacturing system is a new field in the area of distributed manufacturing environment which has many dimensions.

\section{Enterprise Modelling and Integration}

Enterprise Modelling (EM) is the art of combining enterprise knowledge, which adds value to the enterprise, be it a single enterprise, a private or government organization, or a networked enterprise (e.g. extended enterprise, virtual enterprise or smart organization). Enterprise Integration (EI) deals with facilitating information flows, systems interoperability and knowledge sharing among any kind of organization. Enterprise Interoperability, as one of the many facets of EI, provides two or more business entities (of the same organization or from different organizations and irrespective of their location) with the facility to exchange or share information (wherever it is and at any time) and to use functionalities of one another in a 
distributed and heterogeneous environment [36-39]. Molina [40] asserts that Enterprise Modelling has evolved over the last three decades from fact modelling to Knowledge Management while at the same time Enterprise Integration has evolved from computer systems integration and CIM to Enterprise Interoperability and e-commerce.

This paper has provided a short overview of the field in terms of where we stand, and what has to be done next. Moreover, it also proposes an extension of the CIMOSA framework to host extended principles for Enterprise Modelling and Integration, expressed through Figure 1.

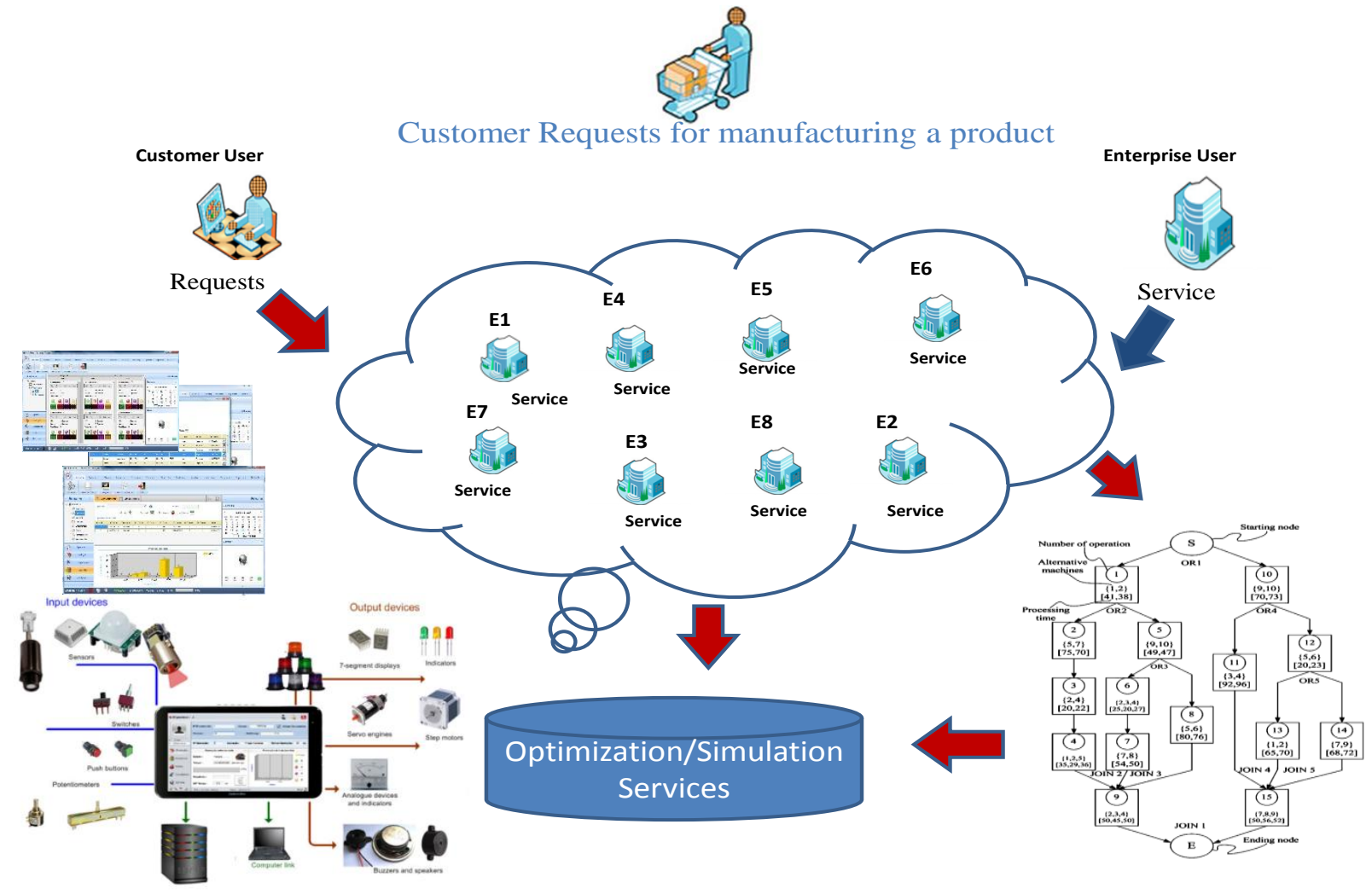

Fig. 1. Networked manufacturing system architecture [41].

Figure 1 illustrates a proposed architecture of a NMS. The NMS starts with a request from the customer whose product task can be handled by the web-based manufacturing service through two different modes namely Customer User (CU) and Enterprise user (EU). CU is defined as a customer or organization that accepts the manufacturing requests from the customers to analyse and process the production tasks with the support of web-based decision system in order to provide a feasible solution in an effective manner. Through web-based manufacturing service (WBMS), it is possible to analyse manufacturing product requests of multiple organizations. On the other side, the functionality of the EU is the same as the CU mode at the initial stage, but due to its self-service providing capability, the requested product can be served entirely by EU itself. In most of the practical cases, a serving of all the product requirements by single EU is almost impossible. Thus, similar to $\mathrm{CU}$, the EU searches for qualified enterprises with the support of web-based decision system to fill the requirements of 
the unfinished tasks such as the finding of potential enterprises, communication with remote servers, interactions with the customers, and remote optimization services.

In this example, the EU can serve as a directive Company in this virtual organization where it can take initiation to interact with the customer, and collaborating with other related enterprises as a coordinator. This way, User, and EU are able to accomplish varied and more demanding production tasks that are unattainable by a single enterprise. However, after finding the necessary product data and the enterprises' information, an effective approach to describe the manufacturing functions requirements and their implementation on networked manufacturing environment is accomplished. Thereafter, with suitable meta-heuristics and simulation techniques, the complex problems in distributed manufacturing environment such as IPPS can be solved to achieve the objectives of the User that can be a solution to the final customer. Some of the basic features of networked manufacturing system are summarized below:

- Networked manufacturing is derived from the concept of a network of enterprises with network based manufacturing as its pattern. It has all the information of enterprises that can provide the procedure of enterprises operation such as feature extraction, data preprocessing, process planning, remote scheduling, and business management in the global environment with the internet as its service.

- Networked manufacturing can provide support to the entire product life cycle.

- It has the ability to improve the competitiveness of the enterprises such that quick response can be achieved.

- The networked manufacturing systems have the capability to reconfigure and reorganize its manufacturing functions when the demands are fluctuating rapidly.

- Collaboration between geographically dispersed enterprises is possible through networked manufacturing environments where effective access to remote resources can lead to lowcost and high-speed product design and manufacturing, based on smart devices, along with the use of wireless communication devices, dashboards and other mobile means, sensors, along with other tools and peripherals.

\section{Conclusion}

In this paper a comprehensive systematic literature review (SLR) of recent and state-ofthe-art papers was carried out, on the role of integrated process planning and scheduling (IPPS) in the context of networked manufacturing environments (NME), in the scope of Industry 4.0, which was vital to draw a framework and to shed light on the future research avenues. The systematic review enabled to draw, as the main conclusion, that IPPS and NME continue to be unexplored thus there is still need for further and even more intense and serious developments regarding IPPS in the context of NME and I4.0. Moreover, the SLR methodology used was useful to identify the gaps in the literature which did lead to further establish future opportunities to conduct the research. It is clear from the conducted study and the developed methodology that further research can assist both academia and industry to develop new tools, techniques, and methodologies for IPPS in NME. Moreover, the subject analyzed on the conducted research study may help further the implementation and improvement in distributed manufacturing environments, to be linked with small and medium enterprises, to further expand their potentialities through well suited IPPS under NME. 
Acknowledgments. This project is funded by Department of Science and Technology (DSTSERB), India under the grant Earlier career research. Moreover, this work has also been supported by COMPETE: POCI-01-0145-FEDER-007043 and FCT - Fundação para a Ciência e Tecnologia within the project scope: UID/CEC/00319/2013.

\section{References}

[1] Liu, F., Liu, J., and Lei, Q., 2002. The Connotation and research development trend of networked manufacturing. Proceedings of China Mechanical Engineering Annual Conference, Beijing, China, 22-27.

[2] Rezaeian, Nikbakhsh Javadian, Reza Tavakkoli-Moghaddam, Fariborz Jolai, "A hybrid approach based on the genetic algorithm and neural network to design an incremental cellular manufacturing system", Applied Soft Computing 11, no. 6, pp:4195-4202, 2011.

[3] Yan J.Q., "Digitized network-based manufacturing," Industrial Engineering and Management, vol.1, pp. 8-11, 2000.

[4] Li, X.Y., and Chaoyong, Z., 2010. An agent-based approach for integrated process planning and scheduling. Expert Systems with Applications, 37, 1256-1264.

[5] Wang, Y., Zhang, Y., Fuh, J., Zhou, Z., Xue, L. and Lou, P. (2008) "A web-based integrated process planning and scheduling system", 4th IEEE Conference on Automation Science and Engineering, in Proceedings, Washington DC, USA, pp.662-667.

[6] Grabowik, C., K. Kalinowski, and Z. Monica. "Integration of the CAD/CAPP/PPC systems." Journal of Materials Processing Technology 164 (2005): 1358-1368.

[7] Varela M.R.L, Trojanowska J., Carmo-Silva S., Costa N.M.L., Machado J., Comparative simulation study of production scheduling in the hybrid and the parallel flow, Management and Production Engineering Review, Vol.8, No.2, July 2017, pp.69-80, DOI:10.1515/mper-2017-0019.

[8] Trojanowska J., Varela M.L.R., Machado J. (2017) The Tool Supporting Decision Making Process in Area of Job-Shop Scheduling. In: Rocha Á., Correia A., Adeli H., Reis L., Costanzo S. (eds) Recent Advances in Information Systems and Technologies. WorldCIST 2017. Advances in Intelligent Systems and Computing, vol 571, pp 490-498, Springer.

[9] Sugimura, N., Hino, R., \& Moriwaki, T. (2001). Integrated process planning and scheduling in holonic manufacturing systems. In Proceedings of IEEE international symposium on assembly and task planning soft research park (Vol. 4, pp. 250-254).

[10] Ueda, K., Fuji, N. and Inoue, R. (2007) 'An emergent synthesis approach to simultaneous process planning and scheduling', Annals of the CIRP, Vol. 56, No. 1, pp.463-466.

[11] Chryssolouris, G., Chan, S., and Cobb, W., 1984. Decision making on the factory floor: An integrated approach to process planning and scheduling. Robotics and Computer-Integrated Manufacturing, 1(3-4), 413-417.

[12] Chryssolouris, G., and Chan, S., 1985. An integrated approach to process planning and scheduling. Annals of the CIRP, 34(1), 413-417.

[13] Sundaram, R. Meenakshi, and Shong-Shun Fu. "Process planning and scheduling-a method of integration for productivity improvement." Computers \& Industrial Engineering 15.1-4 (1988): $296-301$.

[14] Seethaler, R. J., and I. Yellowley. "Process control and dynamic process planning." International Journal of Machine Tools and Manufacture 40.2 (2000): 239-257.

[15] Wang, L. H., \& Shen, W. M. (2003). DPP: An agent-based approach for distributed process planning. Journal of Intelligent Manufacturing, 14, 429-439.

[16] Cai, Ningxu, Lihui Wang, and Hsi-Yung Feng. "GA-based adaptive setup planning toward process planning and scheduling integration." International Journal of Production Research 47.10 (2009): 27452766.

[17] Wong, T.N., Leung, C.W., 2006b. Dynamic shop floor scheduling in multi-agent manufacturing system. Expert Systems with Applications, 31, 486-494.

[18] Shafaei, R., and P. Brunn. "Workshop scheduling using practical (inaccurate) data Part 3: A framework to integrate job releasing, routing and scheduling functions to create a robust predictive schedule." International Journal of Production Research 38.1 (2000): 85-99.

[19] Lee, H., \& Kim, S. S. (2001). Integration of process planning and scheduling using simulation based genetic algorithms. International Journal of Advanced Manufacturing Technology, 18, 586-590. 
[20] Kumar, M., \& Rajotia, S. (2003). Integration of scheduling with computer aided process planning. Journal of Materials Processing Technology, 138, 297-300.

[21] Kumar, Manish, and Sunil Rajotia. "Integration of process planning and scheduling in a job shop environment." The International Journal of Advanced Manufacturing Technology 28.1 (2006): 109-116.

[22] Zhou, Jiehan, and Rose Dieng-Kuntz. "Manufacturing ontology analysis and design: towards excellent manufacturing." Industrial Informatics, 2004. INDIN'04. 2004 2nd IEEE International Conference on. IEEE, 2004

[23] Zhao, F., Zhu, A. and Yu, D. (2006b) 'A hybrid Particle Swarm Optimization (PSO) algorithm schemes for integrated process planning and production scheduling', 6th World Congress on Intelligent Control and Automation, in Proceedings, 21-23 June, Dalian, China, pp.6772-6776.

[24] Li, X., Gao, L., Zhang, G., Zhang, C. and Shao, X. (2008b) 'A genetic algorithm for integration of process planning and scheduling problem', Lecture Notes in Artificial Intelligence, Vol. 5315, pp.495-502.

[25] Li, X., et al., 2010c. An effective hybrid algorithm for integrated process planning and scheduling. International Journal of Production Economics, 126 (2), 289-298.

[26] Moon, I., Lee, S. and Bae, H. (2008) 'Genetic algorithms for job shop scheduling problems with alternative routings', International Journal of Production Research, Vol. 46, No. 10, pp.2695-2705.

[27] Haddadzade, M., M. R. Razfar, and M. Farahnakian. "Integrating process planning and scheduling for prismatic parts regard to due date." World Academy of Science, Engineering and Technology 51 (2009): 64-67.

[28] Baykasoglu, A., Ozbakir L., 2009. A grammatical optimization approach for integrated process planning and scheduling. Journal of Intelligent Manufacturing, 20 (2), 211-221.

[29] Raikumar, M., et al. "A GRASP algorithm for the integration of process planning and scheduling in a flexible job-shop." International Journal of Manufacturing Research 5.2 (2010): 230-251.

[30] Zhou, Yongsheng, et al. "A Generic Model of Reverse Logistics Network Design." ICLEM 2010. Logistics For Sustained Economic Development: Infrastructure, Information, Integration. 2010. 36643670.

[31] Nakandala, Dilupa, Premaratne Samaranayake, and Henry CW Lau. "A fuzzy-based decision support model for monitoring on-time delivery performance: A textile industry case study." European Journal of Operational Research 225.3 (2013): 507-517.

[32] Doyle, J.P., Dougherty, J.D., Heiman, M., Schmidt, E.F., Stevens, T.R., Ma, G., Bupp, S., Shrestha, P., Shah, R.D., Doughty, M.L. and Gong, S., 2008. Application of a translational profiling approach for the comparative analysis of CNS cell types. Cell, 135(4), pp.749-762.

[33] Zhang, Y., Saravanan, A. and Fuh, J. (2003a) 'Integration of process planning and scheduling by exploring the flexibility of process planning', International Journal of Production Research, Vol. 41, No. 3, pp.611-628.

[34] Ming, X. G., Yan, J. Q., Wang, X. H., Li, S. N., Lu, W. F., Peng, Q. J., \& Ma, Y. S. (2008). Collaborative process planning and manufacturing in product lifecycle management. Computers in Industry, 59(2), 154 166.

[35] Chan, F., Kumar, V. and Tiwari, M. (2006) 'Optimizing the performance of an integrated process planning and scheduling problem: an AIS-FLC based approach', 2006 IEEE Conference on Cybernetics and Intelligent Systems, in Proceedings, Bangkok, Thailand, 7-9 June, 1-8.

[36] Kosanke K. and Nell J. G. (Eds.) (1997). Enterprise Engineering and Integration, Proceedings of IFIP International Conference on Enterprise Integration and Modelling Technology, Esprit Project ${ }^{\circ} 21859,1$ ISBN 3-540-63402, Springer-Verlag, Berlin.

[37] OAG. OAGIS, (2001), Open Applications Group Integration Specification, Open Application Group, Inc., Release 7 .2.1, Doc. No. 20011031.

[38] Petrie, Charles J., ed. Enterprise integration modeling: proceedings of the first international conference. MIT Press, 1992.

[39] Vernadat, F.B. (1996), Enterprise Modeling and Integration: Principles and Applications, Chapman \& Hall.

[40] Molina, Arturo, David Chen, Hervé Panetto, Francois Vernadat, and Larry Whitman. "Enterprise integration and networking: issues, trends and vision." Knowledge Sharing in the Integrated Enterprise (2005): 303-313.

[41] Varela, M. L. R., Araújo, A. F., Putnik, G. D., Manupati, V. K., \& Anirudh, K. V. (2016, June). Webbased decision system for effective process planning in network manufacturing environment. In Information Systems and Technologies (CISTI), 2016 11th Iberian Conference on (pp. 1-7). IEEE. 